\title{
Identidade sociomoral, modelos sociais e socialização dos valores
}

\author{
Susana Gonçalves
}

Escola Superior de Educação de Coimbra, Portugal

Resumo

Neste artigo apresenta-se um estudo sobre o impacte das experiências educativas formais e informais sobre a identidade psicossocial dos estudantes do Ensino Superior. O estudo, baseado num inquérito psicossocial, conta com uma amostra de 860 sujeitos (estudantes do Ensino Superior) e está centrado na esfera não-comportamental da moralidade, nomeadamente nas crenças acerca do self e na representação de bem e excelência. Os estudantes foram inquiridos acerca dos seus modelos sociais de excelência, i.e., pessoas que consideram exemplares devido às suas palavras e ações. A metodologia da análise de conteúdo permitiu catalogar as características consideradas como critério para que uma pessoa seja considerada exemplar e um modelo de excelência a seguir; a partir destes critérios inferimos os valores dos estudantes. Os resultados permitem-nos concluir que os padrões de excelência sociomoral não são influenciados pela experiência académica no Ensino Superior. Fatores demográficos, como o sexo e a experiência no contexto familiar, assim como também o estilo educativo parental, são mais influentes na determinação dos valores e crenças sociais e morais dos estudantes do Ensino Superior.

Palavras-chave

Identidade; Moralidade; Valores sociomorais; Estudante do Ensino Superior

\section{Introdução}

No presente artigo apresentamos um estudo sobre a identidade sociomoral do estudante, no qual procurámos compreender as suas posições 
face a si mesmo e ao mundo social (self e mundovisão) e relacioná-las com as variações nos contextos e experiências de vida específicos (cf. Bronfenbrenner, 1979, 1993; Elder, 1980; Smith \& Bond, 1998). No estudo analisamos os valores sociomorais de estudantes do ensino superior, inferidos a partir dos seus modelos sociais da excelência (i.e., aquelas pessoas a quem se reconhece autoridade moral e com quem nos desejamos identificar), e identificamos os efeitos do sexo, do estilo educativo parental e da experiência no ensino superior sobre as variações nas escolhas dos estudantes. O modo como procurámos identificar os valores sociomorais dos estudantes relaciona-se estreitamente com a nossa perspetiva de que os valores não podem ser medidos diretamente, como se se tratasse de dados objetivos, de variáveis descontextualizáveis ou de objetos com uma consistência material mensurável (cf. Van Deth \& Scarbrough, 1995).

O conceito de valor é habitualmente definido como o conjunto de crenças sobre os comportamentos, objetivos e estados desejáveis de um organismo (Feather, 1990; Feldman, 2003; Kilby, 1993; Rokeach, 1973; Van Deth \& Scarbrough, 1995). De acordo com esta definição vulgarizada, os valores são crenças centrais na identidade, na organização do autoconceito e nas disposições ou traços de personalidade (Rokeach, 1973). Os valores influenciam as atitudes e as ações em relação a objetos, pessoas e situações, fornecendo os critérios para justificar opiniões, para orientar a conduta, para escolher entre possibilidades alternativas de decisões, para fazer comparações entre as pessoas e para definir as estratégias de apresentação pessoal e o envolvimento nas interações sociais (Feather, 1990, 1994; Kilby, 1993; Rokeach, 1973). Apesar de possuírem alguma estabilidade, derivada da sua raiz desenvolvimental, os valores mudam com as experiências de vida e quando o sujeito assume novos papéis e responsabilidades sociais (Feather, 1990, 1994; Rokeach, 1973, 1979).

Em sintonia com vários investigadores, consideramos que o estudo da identidade sociomoral beneficia com uma perspetiva interacionista que tenha em conta o processo de socialização da moralidade e os vínculos afetivos de onde emergem as crenças morais (cf. Baumrind, 1992; Hogan, 1973; Mussen \& Eisenberg-Berg, 1977; Youniss \& Damon, 1992). Assim, no nosso estudo procurámos relacionar os padrões de moralidade adotados pelos estudantes e os estilos educativos a que foram sujeitos na infância e adolescência. $O$ final 
da adolescência e a juventude são um dos períodos do ciclo de vida onde a identidade sociomoral está mais sujeita a mudanças, em particular quando os cenários sociais e os contextos de vida são, também eles, marcados pela diferença em relação a períodos de vida anteriores. É precisamente durante este período do ciclo de vida que decorre, para a maioria dos estudantes, a entrada e a frequência do ensino superior. Nesta altura, os pais e a família continuam a ter um peso significativo na gestão de vida do estudante, quer pelos vínculos afetivos, quer pelas dependências económicas. No entanto, a frequência do ensino superior vem dar espaço psicológico a novas formas de autonomia e responsabilidade pessoal, ao mesmo tempo que promove experiências culturais, intelectuais e de relacionamento interpessoal até aí inéditas. Importa saber, por isso, como é que estas novas experiências afetam as conceções de excelência, os valores e as atitudes do estudante.

Os estudos revistos por Pascarella e Terensini (1991) revelam que os estudantes finalistas obtêm resultados mais elevados no que respeita à orientação intelectual, cívica e sociopolítica. A democraticidade e a tolerância política, racial e social evoluem numa direção positiva. As preferências em matéria de valores e atitudes culturais, estéticas e educacionais tornam-se mais elaborados e intelectualmente mais sofisticados; a orientação intelectual e a valorização do saber tornam-se mais nítidas. As conceções acerca da igualdade de oportunidades amplificam-se e o estudante torna-se mais capaz de aceitar e defender os direitos humanos e sociais de outras pessoas e grupos e as suas próprias responsabilidades cívicas. Porém, o efeito do ensino superior sobre muitas destas evoluções é pouco claro e, na maioria dos estudos e para a maioria destas áreas, são dadas explicações alternativas, o que deixa transparecer que o poder do ensino superior, para afetar estas variações, não pode ser estudado à margem de outros contextos e condicionantes experienciais.

Para além dos aspetos educativos e familiares e do estatuto socioeconómico, o sexo é uma das variáveis mais importantes no estudo destas mudanças em geral e no estudo da moralidade e da excelência em particular, pelo que iremos também prestar atenção aos seus efeitos sobre a escolha dos modelos de excelência e a socialização dos valores em estudantes universitários. 


\section{Amostra, metodologia de recolha de dados, medidas e indicadores}

Os resultados foram obtidos junto a uma amostra de 860 sujeitos, maioritariamente constituída por indivíduos do sexo feminino ( $N=671$, o que corresponde a $78.0 \%$ da amostra total), solteiros ( $\mathrm{N}=815$, correspondente a $94.4 \%$ do total), portugueses ( $\mathrm{N}=827$, correspondente a $96.3 \%$ ) e católicos $(\mathrm{N}=705$, correspondente a $82.0 \%$ ). As idades variam entre 17 e 50 anos, com uma média de 20.9 , desvio-padrão de 3.61 e mediana de 20.0, sendo o grupo etário dos 17 aos 19 anos o mais numeroso ( $\mathrm{N}=388,45.3 \%$ do total), seguido do grupo etário dos 20 aos 22 anos ( $\mathrm{N}=266,31.0 \%$ do total). As classes socioeconómicas média ( $N=421,49.0 \%)$ e baixa ( $N=398,46.3 \%$ ) estão representadas de forma relativamente próxima, embora a maioria dos sujeitos se perceba subjetivamente como pertencente à classe média $(\mathrm{N}=608$, $70.7 \%$ ) (ver a caracterização das habilitações e grupos ocupacionais dos pais e a classe social percebida no Anexo 2). A amostra inclui estudantes do $1^{\circ}$ ano e finalistas nos seguintes Cursos: Formação de Professores, Comunicação Social, Filosofia, Língua e Literatura, Matemática, Economia, Sociologia, Psicologia, Direito, Administração Pública e Enfermagem. Os dados foram obtidos por meio de aplicações coletivas do questionário. No presente estudo são analisados os resultados obtidos com dois grupos de questões colocadas aos estudantes a respeito dos seus modelos sociais de moralidade e excelência e respetivos atributos exemplares.

A análise dos resultados teve em conta a idade, o sexo, a experiência no ensino superior e a caracterização do estilo educativo parental dos sujeitos (ver Quadro 1.1). Pela sua relevância no presente estudo, passamos a descrever a metodologia para classificar o estilo educativo.

Integrámos no questionário uma questão (S.4, ver Quadro 1.1) sobre o estilo educativo parental. Para a conceção deste item e do seu modelo de resposta inspirámo-nos no método do diferencial semântico (Osgood, 1952, cit. em Osgood, 1953), no qual um determinado conceito (e.g., tipo de educação) é associado a um par de termos polares descritivos (e.g., boa vs. má). Ao responder a uma série padronizada de pares de termos, o sujeito indica o sentido e a intensidade da associação entre o conceito e cada um dos atributos dados e enuncia a significação do conceito em causa. A questão S.4 refere-se ao tipo de educação recebida na infância e adolescência e procura 
identificar o estilo educativo parental: democrático vs. autoritário/permissivo. Visto que não pretendíamos descrever um conceito simples, mas identificar a perceção de um determinado tipo de relação (estilo educativo parental), selecionámos aqueles descritores que mais frequentemente são enunciados pelas pessoas leigas e descritos na literatura como definindo o estilo democrático, o estilo permissivo e o estilo autoritário. Assim, colocámos no pólo positivo (estilo democrático) os seguintes atributos: inovador, não punitivo, atento, flexível, afetivo, democrático, justo, confiança e exigente. No pólo oposto (estilo autoritário ou permissivo) colocámos os atributos: conservador, punitivo, indiferente, rígido, não-afetivo, autoritário, injusto, controlador e negligente. Estes atributos foram alinhados em nove pares de termos opostos que permitem polarizar o estilo educativo como positivo ou negativo. A ordem dos termos positivo-negativo foi aleatorizada, apresentando-se da seguinte forma: Conservador/Inovador, Punitivo/Não Punitivo, Indiferente/Atento, Rígido/Flexível, Não afetivo/Afetivo, Autoritário/ Democrático, Injusto/Justo, Controlador/Confiança, Negligente/Exigente.

$\mathrm{O}$ indicador do estilo educativo parental corresponde à média dos valores obtidos em 8 destes itens. A análise da consistência interna da escala revelou que a eliminação do item ED_NG_EX (negligente - exigente) fazia subir o alfa de Cronbach (de .85 para .86), pelo que procedemos à sua eliminação. Para a escala, com os restantes 8 itens, a média das intercorrelações é de .43 , oscilando entre o mínimo de .21 e o máximo de 60 .

Para a caracterização das variáveis 'modelos sociais de moralidade' e 'valores sociomorais', a metodologia seguida baseia-se no pressuposto de que o julgamento moral e os sistemas de valores que the dão cobertura devem ser compreendidos nas suas relações com os contextos psicológicos, sociais e culturais em que a moralidade do estudante se define e se expressa. Por esta razão, optámos por não usar nenhuma medida de avaliação do julgamento moral abstrato baseada em dilemas, como é comum nas investigações da linha cognitivo-desenvolvimental. Esta metodologia é mais adequada para o estudo das posições filosóficas do sujeito do que para o estudo da sua identidade e das posições morais situadas no contexto de vida real. Em contrapartida, obtivemos os nossos indicadores através de questões diretas (ver Quadro 1). Pedimos ao estudante que pensasse na pessoa que mais admirava (um modelo a seguir, em virtude da sua vida, palavras ou ações) e que: 
1. dissesse a que categoria, de entre uma lista proposta, pertencia esse modelo;

2. dissesse de quem se tratava;

3. dissesse em que é que essa pessoa se destaca ou destacou;

4. descrevesse as características que fizeram com que a tivesse escolhido.

Apesar da simplicidade das perguntas formuladas, procurámos estudar representações simbólicas complexas: por um lado, identificar a categoria a que pertence a pessoa considerada pelo sujeito como modelo sociomoral; por outro lado, averiguar a existência de uma relação de proximidade afetiva com esse modelo; por fim, inferir, a partir da caracterização desse modelo social exemplar, quais os valores sociomorais integrados no sistema de valores do sujeito. Os dois indicadores do presente estudo (modelos sociais de moralidade e valores sociomorais) basearam-se nas respostas a estas questões.

(a) Modelos sociais de moralidade. Este indicador foi obtido através da análise combinada das questões S.5.a e S.5.b (ver Quadro 1.2), que, depois de agregadas e recodificadas, permitiram a obtenção de 13 categorias distintas de modelos sociais:

- Mãe/Pai = [1];

- Outro familiar = [2];

- Amigo = [3];

- Pessoa conhecida/profissional (professor...) = [4];

- Humanitário = [5];

- Revolucionário = [6];

- Políticos da atualidade = [7];

- Fundador ou líder religioso = [8];

- Ativista = [9];

- Escritores/filósofos/personagens históricas = [10];

- Figuras do mundo do desporto/espetáculo = [11];

- Eu próprio = [12];

- Outros (Deus, ideal de pessoa, personagens fictícios...) = [13] 
As categorias encontradas têm forte semelhança com as categorias identificadas no estudo de Walker, Pitts, Hennig e Matsuba (1995). Os dois sistemas de categorias distinguem-se essencialmente em dois aspetos. Em primeiro lugar, a categoria 'Pessoas da família' de Walker et al. corresponde às nossas duas categorias 'Mãe/Pai' e 'Outros familiares'. Uma vez que a maioria dos sujeitos da nossa amostra estão na faixa etária da adolescência e juventude (contrariamente ao estudo de Walker et al., que, excluindo a infância, se baseou numa amostra de pessoas de todas as faixas etárias), entendemos que deveríamos criar uma categoria para os pais, discriminandoos dos restantes familiares, quer pelo facto de ser numericamente muito elevada a escolha do pai ou da mãe como exemplos de moralidade, quer pelas razões teóricas que explicam essa observação (reconhecendo a importância das figuras parentais durante esta faixa etária).

Em segundo lugar, o sistema de categorias de Walker e colegas inclui ainda a categoria dos 'Jornalistas', inexistente no nosso sistema, e, embora seja comum a categoria 'Ativistas', na nossa classificação acabámos por não classificar nessa categoria nenhuma das respostas obtidas, pois todos os exemplos escolhidos que aí poderiam ser integrados foram catalogados na categoria 'Revolucionários', dada a sua clara atividade política (eis alguns exemplos de pessoas escolhidas pelos sujeitos da nossa amostra: Nelson Mandela, Che Guevara, Gandhi, Martin Luther King, Salgueiro Maia), razão pela qual no Quadro 2 apenas aparecem 12 categorias - a saber:

- Mãe/Pai

- Outros familiares

- Amigos/namorados

- Professores e outros profissionais

- Revolucionários

- Escritores/Filósofos/Personagens históricos

- Artistas/Desportistas/Dirigentes

- Políticos da atualidade

- Fundador ou líder religioso

- Humanitários

- Outras categorias

- Eu próprio 
(b) Valores sociomorais. As características do exemplo moral escolhido (indicador obtido a partir da análise de conteúdo das respostas à questão S.5.c, ver Quadro 1.3) foram tomadas como indicador dos valores do estudante. Supusemos que o padrão de preferências nos poderia servir de indicador dos valores sociomorais do sujeito e das suas posições hierárquicas. Sendo uma questão de resposta aberta, procedemos a uma análise de conteúdo que se traduziu numa taxionomia de 25 valores, agrupados em nove grandes domínios, tal como se pode ver na Grelha de codificação dos valores sociomorais (ver Anexo 1).

Embora a Escala de Valores de Rockech (1973) seja um dos instrumentos mais utilizados para avaliar as preferências por valores, e apesar, também, de esta escala discriminar os valores instrumentais (referidos a modos de comportamento) e os valores finais (referidos a estados finais da existência), considerámos que, no caso dos nossos objetivos, seria mais interessante obter, de um modo espontâneo, uma informação vinda do próprio estudante sobre os seus valores, tomando por base aquilo que diz sobre as qualidades de topo nas pessoas que mais admira.

\section{Quadro 1 - Categorização dos indicadores sobre estilo educativo, modelos sociais de moralidade e valores sociomorais \\ Quadro 1.1 - Estilo educativo parental ${ }^{1}$}

\begin{tabular}{|c|c|c|c|}
\hline \multirow{2}{*}{ Sigla } & \multirow{2}{*}{ Variáveis } & CODIFICAÇÃO & \multirow[t]{2}{*}{ Observações } \\
\hline & & Valor & \\
\hline & $\begin{array}{l}\text { S.4 [Caracterize o tipo de educação que } \\
\text { recebeu durante a infância e } \\
\text { adolescência] }\end{array}$ & & \multirow{10}{*}{$\begin{array}{l}\text { Criação de nova variável, } \\
\text { MED_ED (Estilo } \\
\text { educativo parental) } \\
\text { correspondente ao valor } \\
\text { médio dos itens } \\
\text { ED_CO_IN até } \\
\text { ED_CT_CF }\end{array}$} \\
\hline ED_CO_IN & [Estilo educativo] Conservador - Inovador & [1-6] & \\
\hline ED_PU_NP & [Estilo educativo] Punitivo - Não Punitivo & {$[1-6]$} & \\
\hline ED_IN_AT & [Estilo educativo] Indiferente - Atento & [1-6] & \\
\hline ED_RI_FL & [Estilo educativo] Rígido - Flexível & [1-6] & \\
\hline ED_NA_AF & [Estilo educativo] Não afetivo - Afetivo & [1-6] & \\
\hline ED_AU_DE & [Estilo educativo] Autoritário - Democrático & [1-6] & \\
\hline ED_IN_JU & [Estilo educativo] Injusto - Justo & [1-6] & \\
\hline ED_CT_CF & [Estilo educativo] Controlador - Confiança & [1-6] & \\
\hline ED_NG_EX & [Estilo educativo] Negligente - Exigente & [1-6] & \\
\hline
\end{tabular}


Quadro 1.2: Modelos sociais de moralidade

\begin{tabular}{|c|c|c|c|}
\hline \multirow{2}{*}{ Sigla $^{1}$} & \multirow{2}{*}{ Variáveis } & \multicolumn{2}{|c|}{ CODIFICAÇÃO } \\
\hline & & Rótulo & Valor \\
\hline \multirow[t]{7}{*}{ EX_M_CAT } & $\begin{array}{l}\text { S.5.a [Em que categoria, das abaixo indicadas, se integra a } \\
\text { pessoa que mais admira (cuja vida, palavras ou ações são para si } \\
\text { um modelo a seguir)?] }\end{array}$ & & \\
\hline & \multicolumn{2}{|c|}{ é uma figura histórica } & [1] \\
\hline & \multicolumn{2}{|c|}{ é uma personalidade da atualidade } & [2] \\
\hline & \multicolumn{2}{|c|}{ é uma pessoa da minha família } & [3] \\
\hline & \multicolumn{2}{|c|}{ é uma pessoa das minhas relações pessoais } & [4] \\
\hline & \multicolumn{2}{|c|}{ é um personagem fictício } & [5] \\
\hline & \multicolumn{2}{|c|}{ outra categoria } & [6] \\
\hline EX_M_OUT & \multicolumn{3}{|c|}{ Outra categoria (Qual?) } \\
\hline EX_M_NOM & \multicolumn{3}{|c|}{ S.5.b De que pessoa se trata? } \\
\hline $\begin{array}{l}\text { (var. não } \\
\text { codificada) }\end{array}$ & \multicolumn{3}{|c|}{ S.5.c Em que é que essa pessoa se destaca ou destacou? } \\
\hline
\end{tabular}

\section{Quadro 1.3: Valores sociomorais}

\begin{tabular}{lll}
\hline \multicolumn{1}{c}{ Sigla } & \multicolumn{1}{c}{ Variável } & \multicolumn{1}{c}{ CODIFICAÇÃO } \\
\hline EX_M_CA & $\begin{array}{l}\text { S.5.c [Diga quais as principais } \\
\text { características que mais aprecia nessa } \\
\text { pessoa e fazem com que a tenha } \\
\text { escolhido.] }\end{array}$ & $\begin{array}{l}\text { A variável, sendo de resposta aberta, foi sujeita a análise } \\
\text { de conteúdo, que se traduziu na criação de 25 novas } \\
\text { variáveis, de EX_M_111 até EX_M_9, como se indica } \\
\text { no Quadro 3. }\end{array}$ \\
\hline
\end{tabular}

\section{Resultados: modelos de excelência}

\section{Modelos de excelência: escolhas na esfera pública e na esfera privada}

A análise das frequências e percentagens das respostas dos estudantes, quando inquiridos sobre aquelas pessoas que consideram um modelo a seguir (ver Quadro 2), mostra que 79.9\% dos sujeitos da amostra total escolheram as quatro categorias que se situam na esfera do relacionamento privado ('Mãe/Pai' = 1; 'Outros familiares' = 2 ; 'Amigos/namorados' = 3; e 'Professores e outros profissionais' $=4$ ), com enorme destaque para a categoria 'Mãe/Pai' (49.2\% da amostra)]. Por sua vez, $15.6 \%$ escolheram as categorias da esfera pública. Os restantes $4.5 \%$ escolheram outras categorias (destacam-se escolhas do domínio 
ideal/religioso ou personagens fictícios - anjo da guarda, Peter Pan, etc.). A correlação entre a escolha do exemplo moral e a idade é fraca $[r=.02(\mathrm{~N}=$ 829; $p=.52)]$.

\section{Modelos de excelência: efeitos do sexo}

Comparadas as escolhas de homens e mulheres (ver Quadro 2), encontram-se diferenças estatisticamente significativas na escolha das categorias 'Mãe/Pai', mais valorizada pelas mulheres, e nas categorias 'Escritores/Filósofos/Personagens históricos', 'Artistas/Desportistas/Dirigentes', 'Outras categorias' e 'Eu próprio', mais valorizadas pelos homens.

Procedemos ao teste das diferenças das escolhas dos exemplos morais na esfera privada/pública (EX_M_ESF) entre homens e mulheres, tendo encontrado uma diferença significativa $\left[X^{2}(2)=57.50, p<.01\right]$ que revela existir maior propensão nos homens para fazerem escolhas na esfera pública ou em categorias atípicas de natureza mais abstrata do que nas mulheres, e que estas, pelo contrário, tendem a valorizar mais os exemplos morais do foro do relacionamento privado/familiar.

\section{Modelos de excelência: efeitos do estilo educativo parental}

A escolha das categorias 'Mãe/Pai', 'Outros familiares' e 'Amigos/namorados' está associada com o estilo educativo parental, verificando-se que aqueles que consideram ter recebido uma educação do estilo democrático tendem a escolher mais os pais como exemplos de moralidade do que os que consideram ter recebido uma educação de tipo autoritário ou permissivo; pelo contrário, estes tendem a escolher mais as outras duas categorias (ver Quadro 2). Não deixa de ser interessante notar que é nestas três categorias que se situa a maioria das escolhas dos sujeitos em ambos os grupos e que as percentagens são aproximadas $(73.1 \%$ dos sujeitos do grupo Autoritário/Permissivo e $77.0 \%$ dos sujeitos do grupo Democrático optam por uma desta três categorias) mas as escolhas da categoria 'Mãe/Pai' reduzem substancialmente, no caso dos estilos educativos de tipo autoritário ou permissivo, em favor das outras duas categorias. 
Modelos de excelência: efeitos da experiência no ensino superior

Quando comparadas as escolhas de estudantes do $1^{\circ}$ ano e as dos estudantes finalistas (ver Quadro 2), evidenciam-se associações com a escolha das categorias 'Mãe/Pai' e 'Professores e outros profissionais', sendo a primeira mais escolhida pelos estudantes do $1^{\circ}$ ano e a segunda pelos finalistas. Porém, uma vez que também existem correlações entre estas escolhas e a idade, optámos por efetuar uma análise multivariada da covariância (MANCOVA), tomando a experiência no ensino superior como fator e a idade como covariável. Embora o efeito multivariado para o conjunto das categorias dos exemplos morais não seja estatisticamente significativo [ $\Lambda$ $=0.98, F(12,759)=1.53, p=.11$, os testes univariados revelaram uma diferença estatisticamente significativa entre estudantes do $1^{\circ}$ ano e finalistas na categoria 'Professores e outros profissionais', mais escolhida pelos finalistas $[F(1,770)=5.54, p<.05]$.

Efetuámos uma análise multivariada da covariância para o mesmo fator (experiência no ensino superior), tomando as habilitações e grupo ocupacional dos pais estandardizados (HAB_GO) como covariável. O efeito geral da experiência no ensino superior para o conjunto das categorias dos exemplos morais é estatisticamente significativo $[\Lambda=0.97, F(12,751)=1.85$, $p<.05]$, assim como o efeito geral da covariável $[\Lambda=0.97, F(12,751)=2.13$, $p<.01]$. Os testes univariados revelaram diferenças estatisticamente significativas para as categorias 'Mãe/Pai' $[F(1,762)=5.07, p<.05]$, no sentido de esta categoria ser mais escolhida pelos estudantes do $1^{\circ}$ ano, e para a categoria 'Professores e outros profissionais' $[F(1,762)=12.37$, $p<$ .01], no sentido de ser mais escolhida por estudantes finalistas.

Estes resultados mostram que a experiência no ensino superior não afeta, por si só, a escolha dos modelos, excetuando-se a categoria 'Professores e outros profissionais'. As restantes escolhas parecem estar mais relacionadas com variáveis demográficas, como evidencia a análise dos resultados descritos.

\section{Resultados: valores sociomorais}

Valores sociomorais: quadro geral

Como se pode ver no Quadro 3, os atributos de excelência moral mais usados para caracterizar os modelos são (ver descrição detalhada de cada 
atributo no Anexo 1) a empatia (mencionada por $44.2 \%$ dos sujeitos), a integridade sociomoral (43.0\%), a resistência à adversidade (42.5\%), o altruísmo (26.1\%) e o uso da mente (22.0\%). Cada um dos restantes atributos é referido por menos de $20 \%$ dos sujeitos. Estes dados revelam que são os atributos de natureza sociomoral aqueles que mais contribuem para a avaliação da excelência dos indivíduos e para a consideração de alguém como sendo exemplar a ponto de se poder considerar um modelo sociomoral. Porém, não devemos deixar de salientar a presença de muitos atributos aparentemente estranhos ao domínio sociomoral que foram considerados pelos sujeitos relevantes para a sua escolha. 


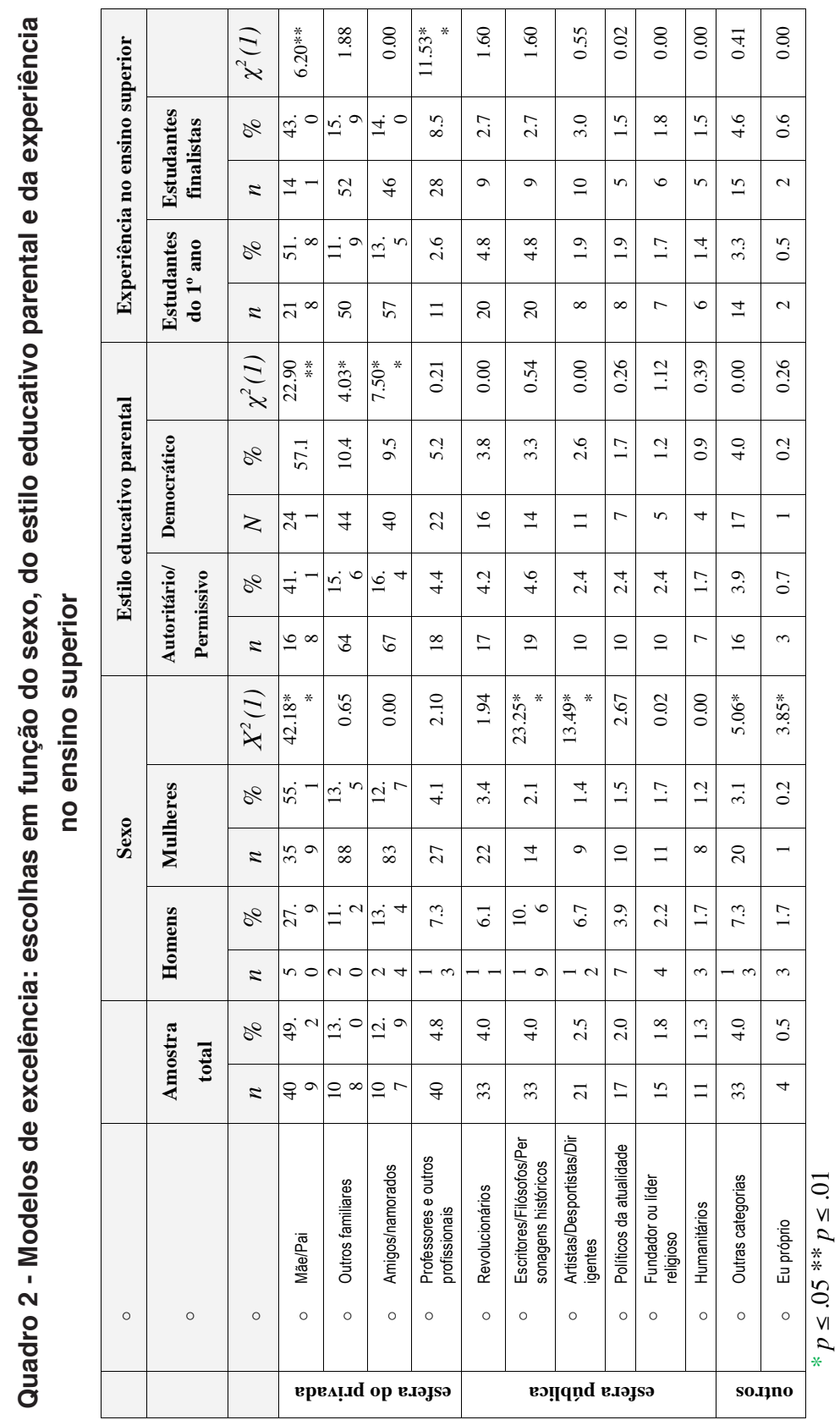


$20 \mid$ Susana Gonçalves

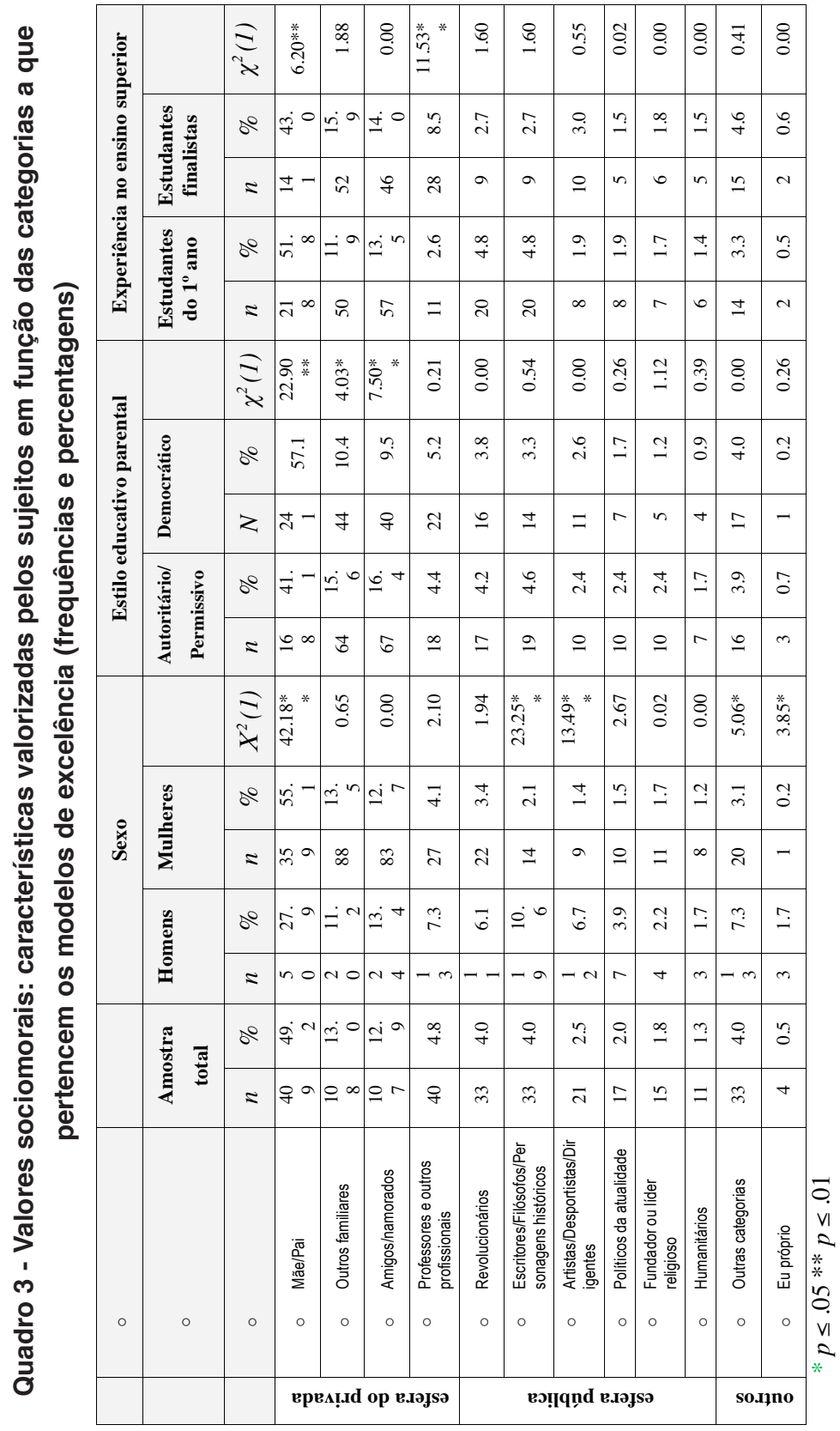


O Quadro 4 mostra as diferenças nas escolhas dos valores em função da pertença do modelo à esfera privada, pública ou outra categoria. Há diferenças significativas nos valores empatia, integridade, resistência, dinamismo e autocentração (mais escolhidos na esfera do privado), notoriedade, inconformismo, criatividade, comunitarismo, idealismo e heroísmo (mais escolhidos na esfera pública) e otimismo (mais escolhido quando o exemplo moral não pertence a nenhuma dessas esferas).

Quadro 4 - Valores: comparação das frequências/percentagens por agrupamento dos modelos de excelência

\begin{tabular}{|c|c|c|c|c|c|c|c|}
\hline & \multicolumn{2}{|c|}{$\begin{array}{c}\text { Modelo de } \\
\text { excelência: } \\
\text { esfera do } \\
\text { privado }\end{array}$} & \multicolumn{2}{|c|}{$\begin{array}{l}\text { Modelo de } \\
\text { excelência: } \\
\text { esfera pública }\end{array}$} & \multicolumn{2}{|c|}{$\begin{array}{l}\text { Modelo de } \\
\text { excelência: } \\
\text { outras } \\
\text { categorias }\end{array}$} & \multirow[b]{2}{*}{$\chi^{2}(2)$} \\
\hline & $n$ & $\%$ & $n$ & $\%$ & $n$ & $\%$ & \\
\hline Empatia & 334 & 50.5 & 17 & 13.1 & 11 & 40.7 & $64.29 * *$ \\
\hline Integridade & 306 & 46.2 & 34 & 26.2 & 12 & 44.4 & $19.26 * *$ \\
\hline Resistência & 295 & 44.6 & 44 & 33.8 & 9 & 33.3 & $9.90 * *$ \\
\hline Altruísmo & 179 & 27.0 & 29 & 22.3 & 6 & 22.2 & 3.07 \\
\hline Uso da mente & 153 & 23.1 & 21 & 16.2 & 6 & 22.2 & 3.72 \\
\hline Autocentração & 141 & 21.3 & 2 & 1.5 & 2 & 7.4 & $33.18 * *$ \\
\hline Simpatia & 110 & 16.6 & 12 & 9.2 & 5 & 18.5 & 4.61 \\
\hline Dinamismo & 105 & 15.9 & 5 & 3.8 & 2 & 7.4 & $15.52 * *$ \\
\hline Otimismo & 78 & 11.8 & 5 & 3.8 & 4 & 14.8 & $7.25 *$ \\
\hline Sabedoria & 63 & 9.5 & 12 & 9.2 & 5 & 18.5 & 0.68 \\
\hline Notoriedade & 46 & 6.9 & 26 & 20.0 & 1 & 3.7 & $24.97 * *$ \\
\hline Respeito & 60 & 9.1 & 5 & 3.8 & 1 & 3.7 & 5.46 \\
\hline Inconformismo & 42 & 6.3 & 18 & 13.8 & 2 & 7.4 & $9.14 *$ \\
\hline Autoconfiança & 47 & 7.1 & 7 & 5.4 & 4 & 14.8 & 1.36 \\
\hline Sobriedade & 38 & 5.7 & 9 & 6.9 & 1 & 3.7 & 0.96 \\
\hline Tranquilidade & 36 & 5.4 & 2 & 1.5 & & & 5.61 \\
\hline Criatividade & 21 & 3.2 & 15 & 11.5 & 1 & 3.7 & $18.21 * *$ \\
\hline Idealismo & 10 & 1.5 & 26 & 20.0 & 1 & 3.7 & $87.68 * *$ \\
\hline Inespecíficos & 25 & 3.8 & 7 & 5.4 & 3 & 11.1 & 2.16 \\
\hline Eficiência & 24 & 3.6 & 6 & 4.6 & 1 & 3.7 & 0.42 \\
\hline Comunitarismo & 5 & 0.8 & 26 & 20.0 & & & $113.64 * *$ \\
\hline Sucesso & 16 & 2.4 & 8 & 6.2 & 1 & 3.7 & 5.24 \\
\hline Emotividade & 9 & 1.4 & & & 1 & 3.7 & 2.41 \\
\hline Religiosidade & 5 & 0.8 & 3 & 2.3 & & & 3.13 \\
\hline Heroísmo & 1 & 0.2 & 4 & 3.1 & & & $15.80 * *$ \\
\hline
\end{tabular}




\section{Valores sociomorais: efeitos do sexo}

Embora não haja diferenças significativas para a maioria dos atributos em função do sexo (ver Quadro 5), existem diferenças significativas para empatia e resistência à adversidade (mais valorizadas pelas mulheres) e para notoriedade, criatividade, idealismo e sucesso (mais valorizados pelos homens).

\section{Valores sociomorais: efeitos do estilo educativo parental}

O estilo educativo parental afeta a escolha de alguns destes atributos: a resistência à adversidade e a autoconfiança são mais valorizadas no grupo de estilo democrático; os sujeitos com estilo educativo autoritário/permissivo escolhem mais atributos inespecíficos (ver Quadro 5).

\section{Valores sociomorais: efeitos da experiência no ensino superior}

A comparação dos estudantes do $1^{\circ}$ ano com os finalistas revela apenas uma diferença significativa na escolha da autocentração (ver Quadro 5). A análise univariada da covariância (ANCOVA) tomando a autocentração como fator, a idade como covariável e a experiência no ensino superior como fator revela que esta tem efeito significativo $[F(1,770)=5.93, p<.05]$, o que não acontece no caso da idade $[F(1,770)=0.56, p=.45]$.

Embora os estudantes se tornem progressivamente menos sensíveis à proteção do outro como elemento relevante para a sua avaliação, os julgamentos não diferem significativamente nos restantes valores. Os resultados parecem indicar que o sistema de valores e preferências sociomorais na avaliação dos outros e das suas qualidades é quase imune à influência do ensino superior. Pelo contrário, os padrões de excelência e os modelos sociais que contribuem para a sua estruturação parecem ser essencialmente organizados no decorrer dos processos informais de educação e socialização. 


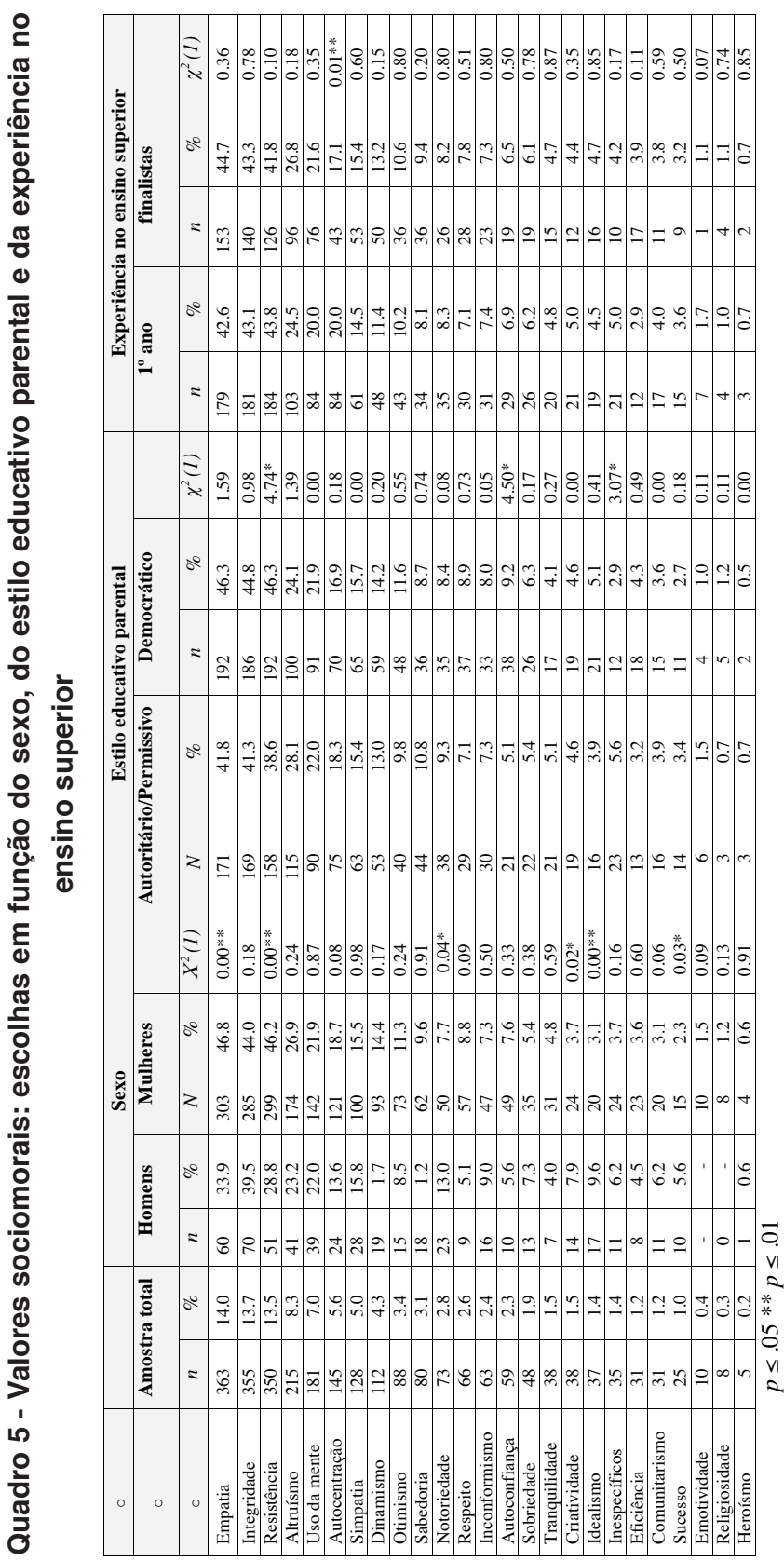




\section{Discussão e conclusões}

O estudo que descrevemos parte de uma abordagem multidimensional da moralidade e explora aspetos como os modelos sociais de excelência e a socialização dos valores sociomorais.

Modelos sociais de excelência. Os modelos sociais de excelência sociomoral são, para a grande maioria dos sujeitos, oriundos da esfera privada, sendo os pais a categoria mais destacada. Quase metade dos sujeitos da amostra escolheram a mãe ou o pai como sendo a pessoa que, por razão da sua vida, palavras ou ações, é aquela que mais admiram e consideram um modelo a seguir. Esta orientação para a esfera da família e das relações afetivas é maior nas mulheres, nos mais jovens e naqueles que beneficiaram, durante a infância e adolescência, de uma educação de tipo democrático (cujos atributos, segundo a nossa escala, incluem o ser inovadora, não punitiva, atenta, flexível, afetiva, democrática, justa e confiante).

Estes resultados corroboram outros estudos que evidenciavam a existência de uma relação estreita entre as preferências sociomorais (e a regulação da moralidade) e os processos de socialização durante a infância e adolescência. Estes estudos salientaram, entre outros fatores, a importância dos aspetos emocionais e afetivos subjacentes aos modelos disciplinares e à indução parental (e.g., Arsenio \& Lover, 1995; Baumrind,1971, cit. em Baumrind 1992; Damon, 1988; Hoffman, 2000) e permitem concluir - o que é suportado pelos nossos resultados - que a escolha dos exemplos morais não é exclusivamente cognitiva, nem é uma decisão baseada no raciocínio puro. Trata-se, antes, de uma preferência fortemente influenciada pelos modelos sociais com maior carga afetiva (Bandura, 1986) que se organiza no decorrer dos processos de interação do sujeito no seu ambiente sociofamiliar e afetivo.

Quando comparados os estudantes recém-chegados ao ensino superior com os finalistas, verificamos que a experiência no ensino superior afeta apenas a escolha de uma categoria, também da esfera do relacionamento privado, que é significativamente mais escolhida pelos estudantes finalistas: a dos 'Professores e outros profissionais'. Esta categoria é substancialmente constituída por escolhas de professores ou mestres (maestro, treinador, orientador de estágio...) de uma atividade praticada pelo 
próprio estudante. Este dado corrobora a ideia de que os professores, entre outros profissionais, podem assumir um papel modelador importante na organização dos valores, atitudes e orientações sociomorais dos estudantes, sobretudo se tivermos em conta que, ao longo do Curso, os estudantes se orientam cada vez mais ativamente para o mundo profissional e tendem, por isso, a valorizar mais as competências no domínio do trabalho. Em consequência, podemos conjeturar que, mesmo neste nível de ensino, os professores continuam a ser modelos sociais relevantes para a formação cívica, profissional e deontológica dos estudantes.

Valores sociomorais. Os atributos de natureza sociomoral são os que têm maior peso na classificação de um indivíduo como modelo de excelência. $\mathrm{Na}$ nossa taxionomia, que integra 25 valores, surgem como virtudes de topo a empatia, a integridade sociomoral, a resistência à adversidade, o altruísmo e o uso da mente. Estes resultados são congruentes com os resultados da literatura sobre as conceções culturais de excelência, da qual se depreende que estas crenças são comuns em várias culturas e que a avaliação da excelência decorre de uma visão integrada do caráter que pressupõe a simultaneidade de qualidades de ordem intelectual, moral, relacional e espiritual. Lembremos os estudos de Li (2001) e de Walker e Pitts (1998), que salientaram que qualidades tais como a diligência, a resistência às dificuldades, a capacidade de resolução de problemas práticos e a inteligência contextual, o gosto pela aprendizagem, a perseverança, a responsabilidade e a humildade são comuns nas avaliações de excelência feitas por pessoas de várias culturas. Um destes estudos (Walker \& Pitts, 1998) também salientou que, para ser considerada moralmente excelente, a pessoa tem que pautar o seu comportamento por valores e princípios sólidos e equilibrar o comportamento com a empatia, a compaixão pelas outras pessoas e o respeito pela comunidade, refletindo tanto as orientações morais da comunidade como as que the são ditadas pela consciência. $O$ estudo empírico sobre pessoas moralmente exemplares em vários campos de atividade também mostra que estas são qualidades de topo nos líderes, nos bons profissionais e nas pessoas que se destacam pelo ativismo social. 
Podemos concluir, a partir dos resultados do nosso estudo, que os estudantes integraram uma visão cultural da excelência e da moralidade e que é a partir dela que procuram aferir os seus critérios de avaliação da excelência. Adotando as ideias de Doise (1998) sobre crenças culturais (como aquelas que se referem às representações dos direitos humanos), diríamos que as crenças e definições da excelência são uma representação coletiva ("significações institucionalizadas") idealizada da moralidade, do bem e da virtude.

No entanto, os resultados não suportam a ideia, assumida por muitos autores, de que a cultura ou o processo de desenvolvimento individual conduz ao estabelecimento de uma hierarquia de valores abstratos. Não encontrámos um perfil único, puro e abstrato do que é ser bom e excelente. Pelo contrário, verificámos que os valores sociomorais e o perfil da excelência se reorganizam em função dos papéis sociais e do domínio de atividade a que os modelos sociais estão associados (família, grupo de amigos, mundo do trabalho, ativismo social...) e também da existência ou não de uma relação de proximidade pessoal/afetiva entre o sujeito e o seu modelo de excelência. Assim, parece que as virtudes do carácter não são percebidas como propriedades abstratas dos modelos nem são alheias às situações em que se revelam ou aos contextos em que são avaliadas.

Também verificámos que as virtudes de topo e as suas combinações num perfil de excelência variam consoante o modelo escolhido se integra nas diferentes categorias da esfera privada ou da esfera pública. Na esfera privada sobressaem os aspetos mais emotivos, afetivos e relacionais e o autocontrolo: a empatia, a integridade sociomoral, a resistência à adversidade, a autocentração e o dinamismo. Estes valores integram a empatia e a integridade sociomoral (que inclui a justiça), ou seja, as duas moralidades de que falava Gilligan (1977, 1993; Gilligan \& Attanucci,1988). Por seu turno, na esfera pública sobressaem a notoriedade, o inconformismo, a criatividade, o idealismo, o comunitarismo e o heroísmo. Parece, portanto, que quando o modelo de referência é alguém que se destaca pelo papel desempenhado na comunidade são valorizados outros atributos da excelência, incluindo o ser mais racional e orientado para o futuro e para a reforma social. 
Além disso, lado a lado com os valores mais facilmente conotados com a moralidade (e.g., empatia, integridade, altruísmo, respeito...), os sujeitos salientaram virtudes não morais (e.g., otimismo, notoriedade, tranquilidade, sucesso...). Concluímos, como Campbell e Christopher (1999), que não é razoável supor a existência de uma hierarquia de valores, na qual os valores morais seriam mais racionais e estariam em conflito com valores de outra natureza, mais afetivos e, supostamente, inferiores na escala de desenvolvimento moral.

Os resultados obtidos permitem-nos sublinhar a importância da afetividade na avaliação dos outros e mostram a existência de uma diferença associada ao género sexual, como tantos autores, sob a égide de Freud (1974a, 1974b) ou de Gilligan (1977, 1993; Gilligan \& Attanucci, 1988), defenderam: as mulheres estão mais orientadas para a esfera da família e das relações interpessoais imediatas, os homens estão mais orientados para a cena pública; as mulheres são mais sensíveis à empatia, os homens à notoriedade e ao sucesso; as mulheres são mais sensíveis à resistência à adversidade (a combatividade no quotidiano), os homens ao idealismo e à criatividade.

De acordo com alguns modelos teóricos, estes dados podem ser interpretados como fruto de uma desigualdade primordial entre os sexos. Porém, não devemos esquecer que crenças sociais como aquelas que se relacionam com o desempenho de papéis sociais não são imunes à influência educativa, aos padrões de moralidade dos agentes educativos e às convenções culturais. Também não devemos ignorar que os conteúdos de uma cultura não são acessíveis da mesma forma a todos os seus membros, devido a restrições sociais, e que a cultura, a masculinidade e a feminilidade tecem entre si relações subliminares (Simmel, 1969) que ultrapassam os meros dispositivos biológicos de diferenciação entre os sexos.

O estilo educativo parental também afeta as escolhas de alguns valores (o estilo democrático promove mais a valorização da resistência à adversidade e a autoconfiança do que os estilos alternativos). Em contrapartida, a experiência no ensino superior afeta apenas um dos 25 valores: a autocentração, que reduz substancialmente nos estudantes finalistas - o que reflete o progresso do estudante em direção à autonomia psicológica. Relembramos que, no âmbito da nossa taxionomia de valores, o 
termo autocentração se aplica quando o estudante valorizou comportamentos do seu modelo sociomoral que enunciam a sua própria necessidade de ser protegido ou apoiado no seu desenvolvimento pessoal; muitas destas respostas também se relacionam com o contributo do modelo para o bemestar da família, sendo dadas quando o modelo é escolhido entre as pessoas da sua própria família, nomeadamente o pai ou a mãe.

Em suma, os padrões de excelência sociomoral são muito pouco influenciados pela experiência no ensino superior, ou são-no de forma difusa, sendo outros processos de socialização, particularmente os que decorrem no espaço da família, aqueles que mais afetam as crenças e valores sociomorais do estudante. Esta conclusão requer, no entanto, um teste empírico por meio de outros estudos. Seriam particularmente relevantes estudos comparativos nos quais os estudantes do ensino superior fossem comparados com jovens que não prosseguiram para o ensino superior e a comparação entre estudantes e diplomados do ensino superior (agrupados em função do tempo de conclusão dos estudos).

\section{Notas}

1 Questão colocada aos sujeitos:

S.4.- Apresentam-se de seguida vários pares de atributos que podem servir para caracterizar pessoas e formas de relacionamento entre elas. Em cada par de atributos aparecem dois termos opostos e distanciados por uma escala que vai de 1 a 6 .

Pense sobre o tipo de educação que recebeu (dos seus pais ou outra(s) pessoa(s) que tenha $(\mathrm{m})$ cuidado de si durante a infância e adolescência). Caracterize esse tipo de educação, escolhendo, para cada um dos pares de atributos abaixo apresentados, o número que melhor representa a sua opinião, sabendo que 1,2 e 3 estão mais próximos do termo da coluna à esquerda (sendo 1 o mais próximo) e que 4,5 e 6 estão mais próximos da coluna à direita (sendo 6 o mais próximo).

\begin{tabular}{|c|c|c|}
\hline Conservador & $\leftarrow$---- 1 ---- 2 ---- 3 ---- 4 ---- 5 ---- 6 ---- $\rightarrow$ & Inovador \\
\hline Punitivo & $\leftarrow$---- 1 ----- 2 ----- 3 ---- 4 ----- 5 ----- 6 ----- $\rightarrow$ & Não punitivo \\
\hline Indiferente & $\leftarrow$----- 1 ----- 2 ----- 3 ----- 4 ----- 5 ----- 6 ----- $\rightarrow$ & Atento \\
\hline Rígido & 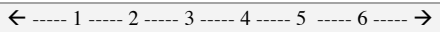 & Flexível \\
\hline Não afetivo & $\leftarrow$---- 1 ----- 2 ----- 3 ---- 4 ---- 5 ---- 6 ---- $\rightarrow$ & Afetivo \\
\hline Autoritário & $\leftarrow$----- 1 ----- 2 ----- 3 ----- 4 ----- 5 ----- 6 ---- $\rightarrow$ & Democrático \\
\hline Injusto & $\leftarrow$----- 1 ----- 2 ----- 3 ----- 4 ----- 5 ----- 6 ----- $\rightarrow$ & Justo \\
\hline Controlador & $\leftarrow$----- 1 ----- 2 ----- 3 ----- 4 ----- 5 ----- 6 ----- $\rightarrow$ & Confiante \\
\hline Negligente & 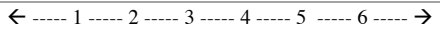 & Exigente \\
\hline
\end{tabular}


2 As variáveis EX_M_CAT e EX_M_OUT e EX_M_NOM foram agregadas na variável R_EX_M_C (categoria do exemplo moral). A partir desta variável foi ainda criada uma outra: 'Exemplo moral - Esferas' (EX_M_ESF), de três níveis: esfera do privado $=$ [1], aglutinando os grupos 1 até 4 ; esfera pública $=[2]$, aglutinando os grupos 5 até 11 ; e outros $=[3]$, aglutinando os grupos 12 e 13 .

\section{Referências}

Arsenio, W., \& Lover, A. (1995). Children conceptions of sociomoral affect: Happy victimizers, mixed emotions, and other expectancies. In M. Killen \& D. Hart (Eds.), Morality in everyday life: Developmental perspectives (pp. 87-130). Cambridge: Cambridge University Press.

Bandura, A. (1986). Social foundations of thought and action. New Jersey: Prentice Hall.

Baumrind, D. (1992). Leading an examined life: The moral dimension of daily conduct. In W. M. Kurtines, M. Azmitia \& J. L. Gewirtz (Eds.), The role of values in psychology and human development (pp. 256-280). New York: John Wiley \& Sons.

Bronfenbrenner, U. (1979). The ecology of human development: Experiments by nature and design. Cambridge, MA: Harvard University Press.

Bronfenbrenner, U. (1993). The ecology of cognitive development: Research models and fugitive findings. In R. W. Wozniak \& K. W. Fischer (Eds.), Development in context (pp. 3-44). Hillsdale, NJ: Erlbaum.

Campbell, R. L., \& Christopher, J. C. (1999). Self and values: An interactivist foundation for moral development. Retirado de http://hubcap.clemson.edu/ campber/ index.html

Damon, W. (1988). The moral child: Nurturing children's natural moral growth. New York: Free Press.

Doise, W. (1998). Les droits de l'homme comme représentations sociales. In A. D. Gomes \& J. P. Valentim (Orgs.), Psicologia e sociedade: Ciclo de conferências (pp. 67-92). Coimbra: Faculdade de Psicologia e de Ciências da Educação da Universidade de Coimbra.

Elder, G. H. (1980). Adolescence in historical perspective. In J. Adelson (Ed.), Handbook of adolescence psychology (pp. 3-46). New York: John, Wiley \& Sons.

Feather, N. T. (1990). Bridging the gap between values and actions: Recent applications of the expectancy-value model. In E. T. Higgins \& R. M. Sorrentino (Eds.), Handbook of motivation and cognition: Foundations of social behavior (pp. 151192). New York: Guilford Press.

Feather, N. T. (1994). Values, national identification and favouritism towards the ingroup. British Journal of Social Psychology, 33, 467-476.

Feldman, S. (2003). Values, ideology, and structure of political attitudes. In D. O. Sears, I. Huddy \& R. Jervis (Eds.), Oxford handbook of political psychology (pp. 477508). Oxford: University Press.

Freud, S. (1974a). A sexualidade feminina. In J. Strachey (Ed.), Edição standard brasileira das Obras Psicológicas Completas de Sigmund Freud (Vol. XIII, pp. 259-279). Rio de Janeiro: Imago. 
Freud, S. (1974b). O mal-estar na civilização. In J. Strachey (Ed.), Edição standard brasileira das Obras Psicológicas Completas de Sigmund Freud (Vol. XIII, pp. 81-171). Rio de Janeiro: Imago.

Gilligan, C. (1977). In a different voice: Women's conceptions of self and of morality. Harvard Educational Review, 47, 481-517.

Gilligan, C. (1993). In a different voice: Psychological theory and women's development. Cambridge: Harvard University Press.

Gilligan, C., \& Attanucci, J. (1988). Two moral orientations: Gender differences and similarities. Merrill-Palmer Quarterly, 34, 223-237.

Hoffman, M. L. (2000). Empathy and moral development: Implications for caring and justice. Cambridge: Cambridge University Press.

Hogan, R. (1973). Moral conduct and moral character: A psychological perspective. Psychological Bulletin, 79(4), 217-232.

Kilby, R. W. (1993). The study of human values. Lanham: University Press of America.

Li, J. (2001). High abilities and excellence: A cultural perspective. Good Work Project Report Series, $n^{\circ}$ 12. Retirado de http://www.goodworkproject.org/ GoodWork12.pdf

Mussen, P., \& Eisenberg-Berg, N. (1977). Roots of caring, sharing and helping. San Francisco: W.H. Freeman.

Osgood, C. (1953). Method and theory in experimental psychology. New York: Oxford University Press.

Pascarella, E. T., \& Terenzini, P. T. (1991). How college affects students: Findings and insights from twenty years of research. San Francisco: Jossey-Bass.

Rokeach, M. (1973). The nature of human values. New York: Free Press.

Rokeach, M. (1979). Understanding human values. New York: Free Press.

Simmel, G. (1969). Cultura feminina. Alfragide: Galeria Panorama.

Smith, P. B., \& Bond, M. H. (1998). Social psychology across cultures (2 ${ }^{\mathrm{a}}$ ed.). Hertfordshire: Prentice-All Europe.

Van Deth, J. W., \& Scarbrough, E. (1995). The concept of values. In J. W. van Deth \& E. Scarbrought (Eds.), The impact of values (pp. 21-47). Oxford: Oxford University Press.

Walker, L. J., \& Pitts, R. (1998). Naturalistic conceptions of moral maturity. Developmental Psychology, 34(3), 403-419.

Walker, L. J., Pitts, R. C., Hennig, K. H., \& Matsuba, M. K. (1995). Reasoning about morality and real-life moral problems. In M. Killen \& D. Hart (Eds.), Morality in everyday life (pp. 371-408). Cambridge: Cambridge University Press.

Youniss, J., \& Damon, W. (1992). Social construction in Piaget's theory. In H. Beilin \& P. Pufall (Eds.), Piaget's theory: Prospects and possibilities (pp. 267-289). Hillsdale, NJ: Erlbaum. 
SOCIOMORAL IDENTITY, SOCIAL MODELS AND SOCIALIZATION OF VALUES

\begin{abstract}
The paper introduces a psychosocial study about values, attitudes and behaviours of college students. A sample of 860 participants answered a questionnaire whose purposes where, among others, to clarify the impact of formal and informal educational experiences on social identity in university students. The research methodology will be presented and part of the results shown and discussed. Reported data are centred at the non-behavioural sphere of morality, namely the representation of good and excellence and the beliefs about self and worldviews. Students where inquired about their social models of excellence, i.e., people who excel and which the subject considers exemplar, due to his/her words and behaviours. Content analyses made it possible to catalogue the characteristics considered as criteria to judge a person as a model to be followed. This leads to the inference of student's social values. Results show that the patterns of sociomoral excellence are uninfluenced by the college experience. Other socialization processes, particularly those evolving at the family sphere, such as the educational style of parents, are much more influential upon social and moral beliefs and values of the student. Gender is another factor revealing significant effects.
\end{abstract}

Keywords

Identity; Morality; Social and moral values; University students 


\section{IDENTITÉ SOCIO-MORALE, MODĖLES SOCIALES ET SOCIALISATION DES VALUES}

\section{Résumé}

Cet article présente une étude sur l'impact des expériences formelles et informelles d'éducation sur l'identité psychosociale des étudiants de l'enseignement supérieur. 860 étudiants ont répondu à un questionnaire dont les buts sont, entre autres, de clarifier l'impact du formels et informels d'expériences pédagogiques sur l'identité sociale chez les étudiants universitaires. Les étudiants ont été interrogés sur leurs modèles sociaux de l'excellence, à savoir: des personnes qui trouvent des copies en raison de leurs paroles et leurs actions, la représentation du bien et d'excellence et les croyances sur soi et visions du monde. La méthodologie d'analyse de contenu a permis de classer les caractéristiques considérées comme un critère pour qu'une personne puisse être considérée comme exemplaire et un modèle d'excellence à suivre. Cela nous permet d'inférer les valeurs sociales des étudiants. Les résultats nous permettent de conclure que les normes de l'excellence sociomoral sont pas influencés par l'expérience académique dans l'enseignement supérieur. Autres processus de socialisation, en particulier ceux évoluant à la sphère familiale, tels que le style éducatif des parents, sont beaucoup plus influents sur les croyances sociales et morales et les valeurs de l'étudiant. Les facteurs démographiques, tels que le sexe et l'expérience au sein de la famille, sont les plus influents dans la détermination des valeurs et des croyances morales et sociales des étudiants.

Mots-clé

Identité; Moralité; Valeurs sociales et morales; Etudiants universitaires

Recebido em Maio/2010

Aceite para publicação em Fevereiro/2012

Toda a correspondência relativa a este artigo deve ser enviada para Susana Gonçalves: susana@esec.pt 


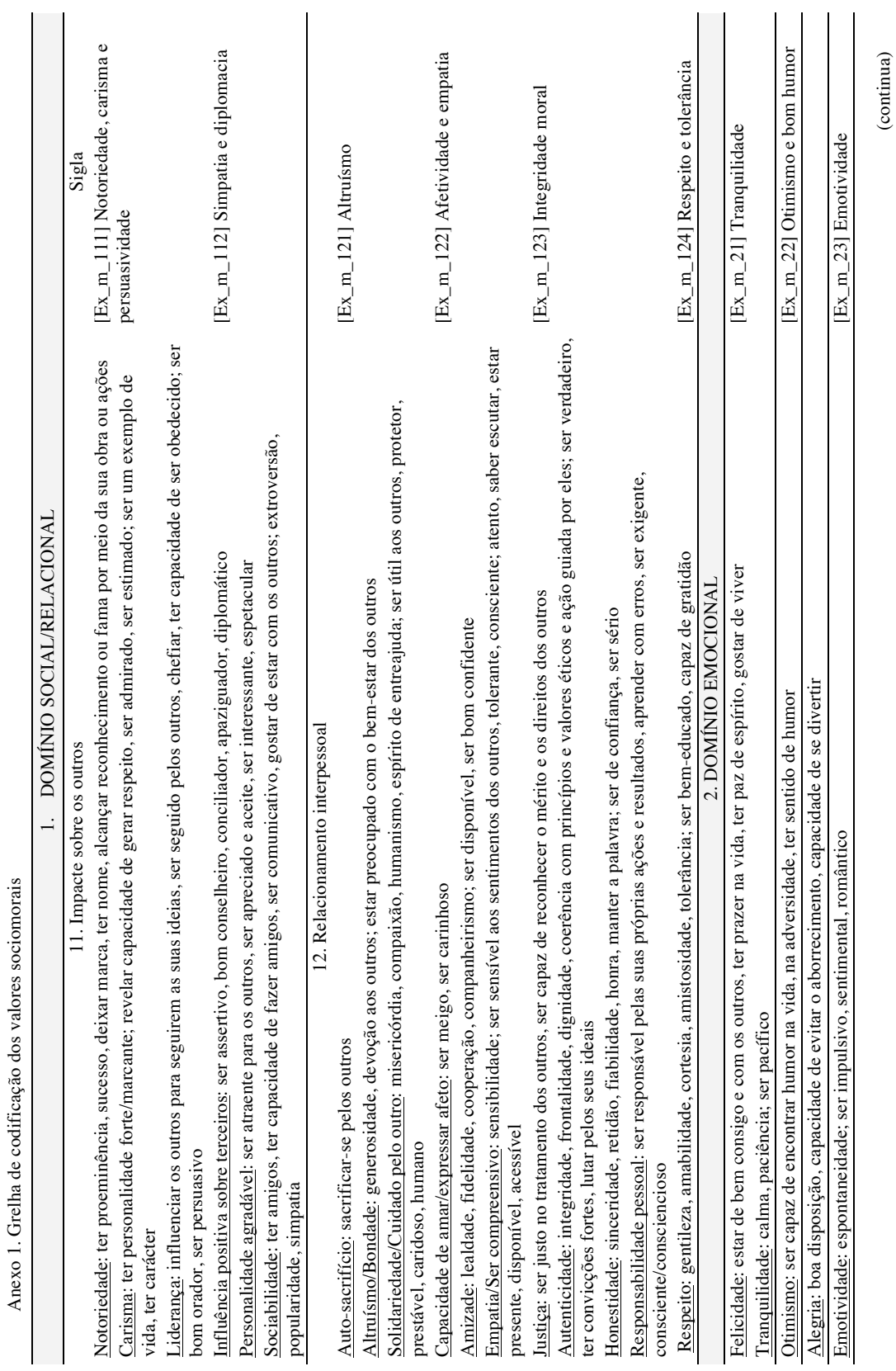




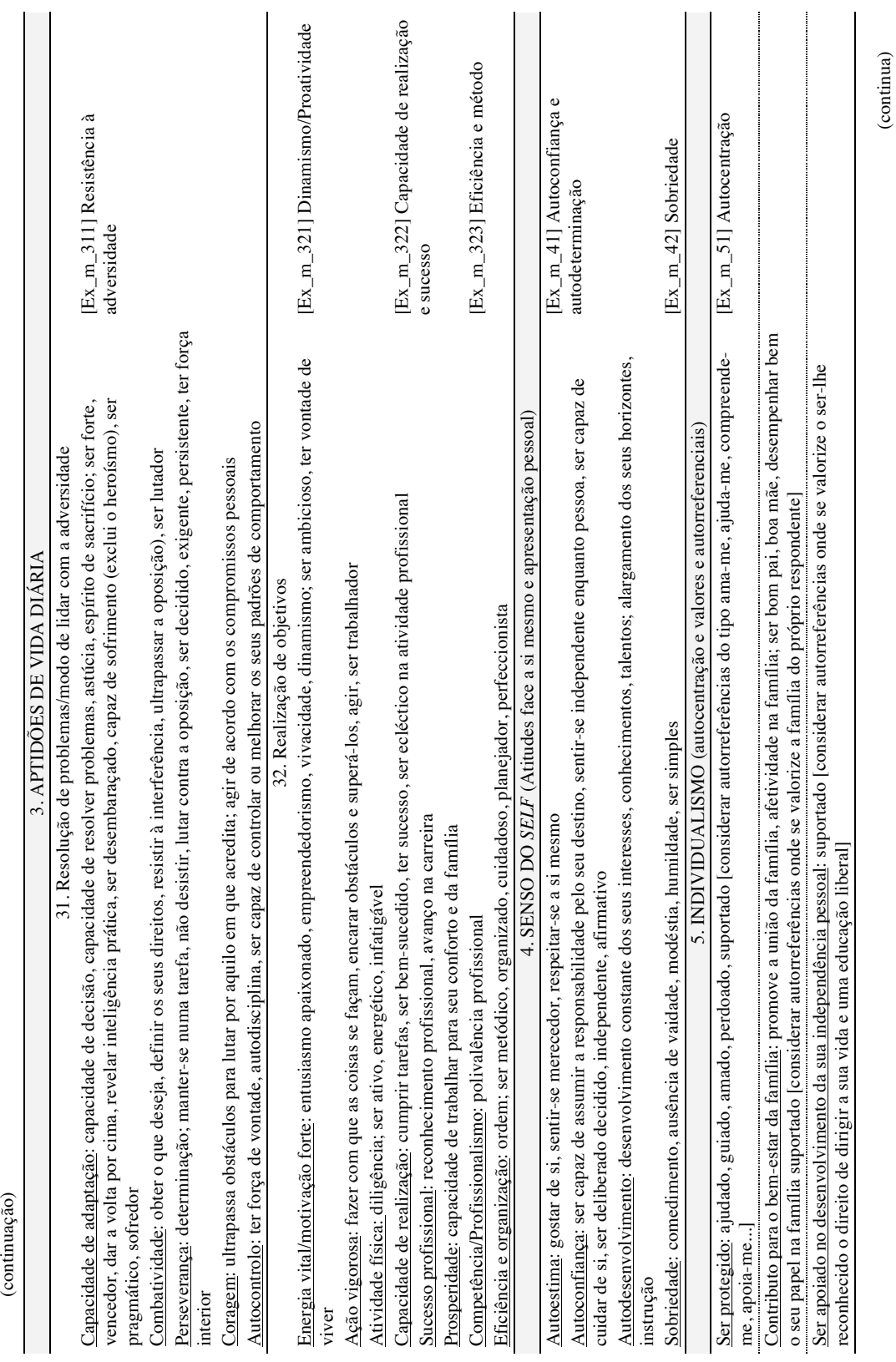




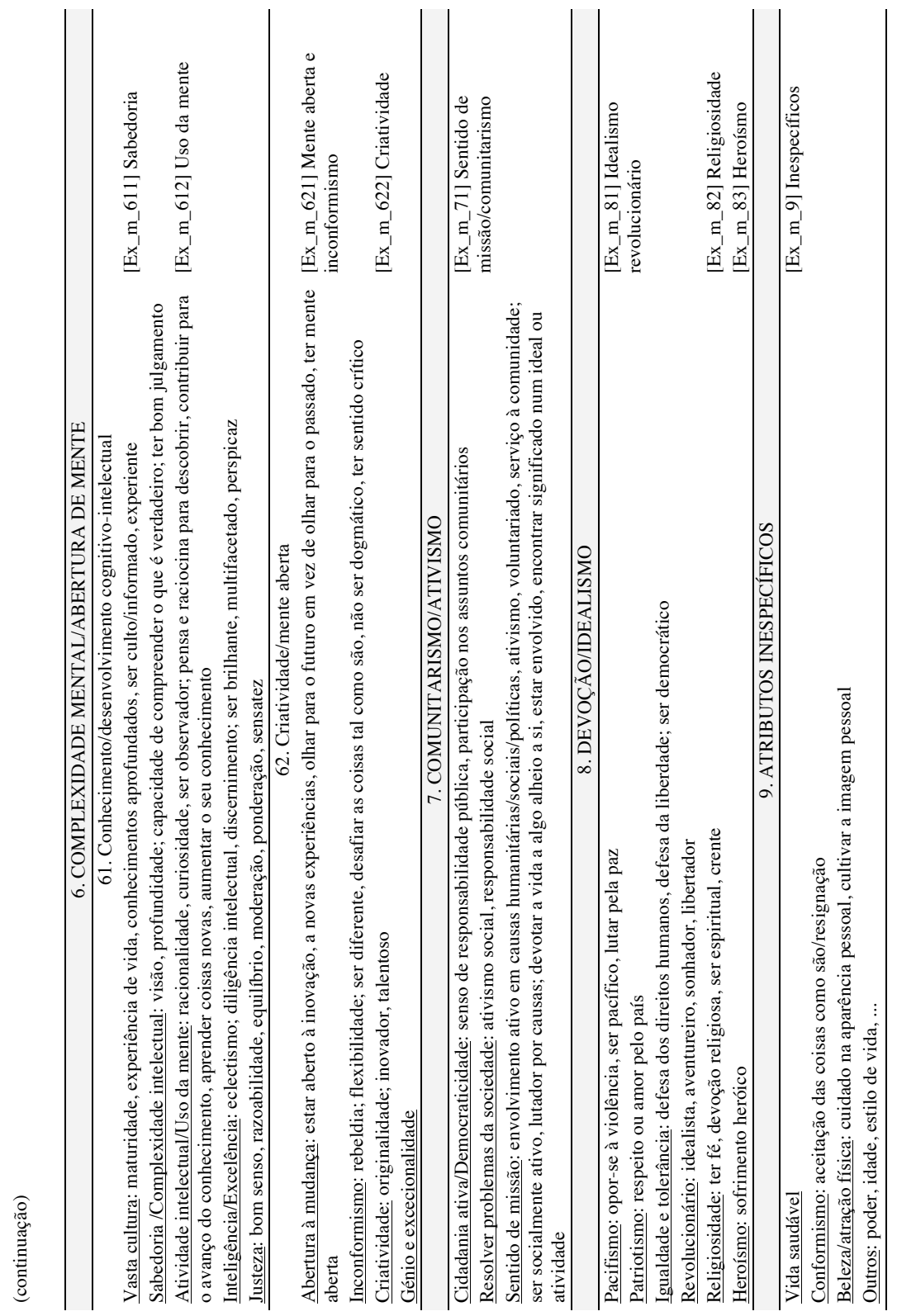


Anexo 2

Quadro 6: Habilitações e grupos ocupacionais dos pais $(\mathrm{N}=860)$

\begin{tabular}{|c|c|c|c|c|c|}
\hline \multirow{2}{*}{ Característica } & \multirow{2}{*}{ Categoria } & \multicolumn{2}{|c|}{ Pai } & \multicolumn{2}{|c|}{ Mãe } \\
\hline & & $n$ & $\%$ & $n$ & $\%$ \\
\hline \multirow[t]{9}{*}{ Habilitação } & Nunca frequentou a escola & 7 & 0.8 & 11 & 1.3 \\
\hline & Instrução primária incompleta & 27 & 3.2 & 34 & 4.0 \\
\hline & Instrução primária completa & 331 & 38.8 & 322 & 37.6 \\
\hline & $2^{\circ}$ ano liceal (atual $6^{\circ}$ ano) & 99 & 11.6 & 111 & 13.0 \\
\hline & $5^{\circ}$ ano liceal (atual $9^{\circ}$ ano) & 109 & 12.8 & 104 & 12.1 \\
\hline & $7^{\circ}$ ano liceal (atual $11^{\circ} / 12^{\circ}$ ano) & 117 & 13.7 & 98 & 11.4 \\
\hline & Curso médio/bacharelato & 62 & 7.3 & 54 & 6.3 \\
\hline & Curso superior/licenciatura & 85 & 10.0 & 99 & 11.6 \\
\hline & Pós-graduação/mestrado/doutoramento & 16 & 1.9 & 23 & 2.7 \\
\hline \multirow[t]{9}{*}{ Grupo ocupacional } & Empr. Serviços/Comércio/Administrativos & 94 & 11.2 & 96 & 11.5 \\
\hline & Trabalhadores Qualificados/Especializados & 264 & 31.5 & 39 & 4.7 \\
\hline & $\begin{array}{l}\text { Trabalhadores não Qualificados/não } \\
\text { Especializados }\end{array}$ & 62 & 7.4 & 187 & 22.3 \\
\hline & Não Ativos & 94 & 11.2 & 51 & 6.1 \\
\hline & Domésticas & - & - & 246 & 29.4 \\
\hline & Quadros Superiores & 83 & 9.9 & 23 & 2.7 \\
\hline & Quadros Médios & 36 & 4.3 & 58 & 6.9 \\
\hline & Técnicos Especializados & 68 & 8.1 & 78 & 9.3 \\
\hline & Pequenos Proprietários & 136 & 16.2 & 60 & 7.2 \\
\hline
\end{tabular}

Quadro 7: Caracterização sociodemográfica da amostra: Classe social percebida $(\mathrm{N}=860)$

\begin{tabular}{llrr}
\hline Característica & Categoria & $n$ & $\%$ \\
\hline Classe social & Classe alta ou média alta & 50 & 5.8 \\
& Classe média & 608 & 70.7 \\
& Classe média baixa ou baixa & 202 & 23.5 \\
\hline
\end{tabular}

